\title{
Types of handwriting and signs of dysgraphia in children and adolescents with learning difficultie
}

Universidade Federal do Rio Grande do Norte - UFRN, Natal, Rio Grande do Norte, Brasil.

2 Universidade de São Paulo, Faculdade de Odontologia de Bauru - FOB-USP, Bauru, São Paulo, Brasil.

Research support source: Instituto ABCD

Conflict of interests: Nonexistent

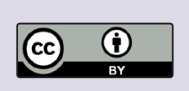

Received on: April 21, 2020

Accepted on: September 15, 2020

Corresponding address:

Monica Teixeira Borges

Praça João Leopoldo n'25,

CEP 64601-355 - Picos, Piauí, Brasil

E-mail: mntborges@gmail.com

\section{ABSTRACT}

Purpose: to characterize handwriting aspects of children and adolescents with complaints of learning difficulties, based on the type of handwriting they used.

Methods: thirty-two children and adolescents participated in the study. They were first to eighth graders of both sexes, aged 7 to 15 years, with complaints of learning difficulties. The participants were divided according to the type of letter they used: SG1 (block letters), SG2 (cursive letters), and SG3 (mixed letters). A themed composition was analyzed with an adapted Dysgraphia Scale. Afterwards, the score obtained in the items of the Dysgraphia Scale was statistically analyzed, comparing the results between the three groups, between SG1 and SG2, SG1 and SG3, and SG2 and SG3. Appropriate statistical tests were applied, considering as significant the p-value $<0.05$.

Results: no difference was found regarding the groups' age and schooling level. As for the items in the Scale, there was a difference between the three groups regarding irregular spacing in between words, collisions and adhesions, and total score. Signs of dysgraphia were observed in the three groups, according to the Scale's criteria.

Conclusion: changes in handwriting are common in children with learning difficulties, especially when they write using cursive and mixed letters.

Keywords: Child Development; Handwriting; Assessment 


\section{INTRODUCTION}

Writing is a complex process that involves having previously learned to read - which makes it more complicated than reading ${ }^{1}$. Acquiring it requires a quite long and demanding process that begins early - around two years old, when the first graphic movements are produced - and is consolidated later, in adolescence. However, the most substantial changes in the characteristics of one's handwriting take place between five and 10 years old ${ }^{2}$.

The acquisition of writing is the sum of aspects related to maturation, development, and integration of the central nervous system ${ }^{3}$, motor components ${ }^{4}$, and the social context to which the child belongs ${ }^{5}$.

In principle, the act of writing involves an extensive area of the brain's left hemisphere, comprising twelve cortical areas. Of these, three are considered primarily specific for writing (left superior frontal sulcus/middle frontal gyrus area; left intraparietal sulcus/superior parietal area; and right cerebellum) ${ }^{3}$. Also, the cognitive and motor components related to the writing performance include fine motor control (manual adjustment, bilateral integration, and motor planning), visualmotor integration, visual perception, kinesthesia, and sustained attention ${ }^{4}$.

Cursive writing requires the mastery of movements that represent an excessive effort on the part of children that are not even able yet to easily hold the pencil and control it ${ }^{6}$. Hence, in the context of Brazilian education, it is recommended that handwritten block capitals be used first, as they are easier to recognize and write. Later, the students are led to acquire the cursive letters, as it allows for more agile writing - although its continuous tracing is not simple ${ }^{7}$. A study evidenced that the differences in graphic patterns tend to decrease as the child grows older ${ }^{8}$.

Changes in the cognitive and motor components related to the writing process can change the perceptual organization, spatial-temporal structuring, and body scheme development. This process can result in changes in the visual-perceptual integration capacity, topological disorders, abnormal body posture, difficulty to hold the pencil, and, as a result, a slow and tiresome handwriting ${ }^{9}$. Children with developmental coordination disorders present these characteristics since they have problems producing writing, especially to form letters, regardless of their age ${ }^{10}$.

Hand dominance is another factor that interferes with manual dexterity ${ }^{11}$. Thus, laterality may influence the writing performance, given that children with ambidexterity, inhibited left-handedness, and/or crossdominance have risk factors for dysgraphia?.

The unbalance in the functioning of the abovementioned components may trigger dysgraphia, which has two meanings: It can refer to orthographic changes, or to deficits that affect either the motor planning or other processes involved in producing writing ${ }^{12}$. It can be characterized by slow writing, illegible writing, poorly organized letters in space (too short letters, non-straight lines, misplaced letters in the line, etc.), and misspellings ${ }^{13}$.

Dysgraphia is defined by the DSM- 5 as the persistent and impairing writing skill difficulty, which can be one of the manifestations of the specific learning disorder ${ }^{14}$. However, it can be present both in children with learning disorders and those with learning difficulties. It can occur in children with good academic performance, as well ${ }^{15}$.

Learning to read and write requires systematic instruction, a process to which the school is directly related. Most of the school activities involve writing skills ${ }^{5}$. Nonetheless, most of the teachers are unfamiliar with important aspects of the children's learning development because they lack the structured knowledge about the psychomotor functions necessary to acquire writing $^{16}$. When they refer to the children's writing difficulties, the teachers relate them to the orthographic aspects instead of letter shape ${ }^{17}$.

Given the importance of the knowledge of handwriting, this study aimed to characterize aspects of the handwriting of children with complaints of learning difficulties, according to the type they used, to verify signs suggestive of dysgraphia.

\section{METHODS}

This is a cross-sectional, observational, quantitative, individuated study, approved by the Research Ethics Committee of the Hospital Universitário Onofre Lopes, Brazil, under protocol no. 1.012.635/2015. The data was collected from participants of a project for children with learning difficulties, which takes place in the teaching clinic of the Universidade Federal do Rio Grande do Norte, Rio Grande do Norte, Brazil. Its objective is the assessment and intervention of children with learning difficulties, specifically regarding their reading and writing. 


\section{Participants}

The sample consisted of 32 children and adolescents of both sexes, aged 7 to 15 years, whose schooling ranged from first to eighth grade, encompassing elementary and middle school.

The inclusion criteria were: (a) children and adolescents with specific complaints of learning difficulties with consequences on their school achievements in the preestablished age range; (b) participants of a specific project for children with learning difficulties whose parents signed the informed consent form (ICF), (c) participants of the said project who signed the informed assent form (IAF), (d) children and adolescents that wrote spontaneously in the assessment process. Participants that presented other emotional, physical, and health complaints impairing their school performance were excluded, as well as the samples of children and adolescents who used a pen and/or had previously written some lines before beginning their text.

The groups were composed based only on the analysis of the sample of writing, and the participants were divided, according to the type of handwriting they used, resulting in three groups. It was decided to form the groups based on the characteristics of their handwriting because the child's chronological age or grade in school is not always compatible with their performance. Hence, regardless of schooling or age group, the handwriting, characterized by its type of letter, was the object of this study:

- Study group 1 (SG1): Eight children/adolescents with learning difficulties that wrote with block letters;

- Study group 2 (SG2): 12 children/adolescents with learning difficulties that wrote with cursive letters;

- Study group 3 (SG3): 12 children/adolescents with learning difficulties that wrote with mixed letters (i.e., sometimes block, sometimes cursive letters).

\section{Instrument and Procedures}

The instrument used was the Dysgraphia Scale proposed by Lorenzini $(1993)^{18}$, based on the Ajuriaguerra's Dysgraphia Scale (1971). It was adapted for this study because the instrument analyzes the handwriting resulting from a dictation, whereas in this study it was decided to analyze the writing based on the theme "The haunted house". For the writing, the participants were supplied with a white paper and a no. 2 pencil. They were then told the theme for the composition, which they wrote in a single session, with no time limits. After the activity, the assessor analyzed their resulting handwriting. The scale enables the writing to be quantitatively analyzed based on scores given to 10 analysis items: (1) fluctuating lines; (2) descending and/or ascending lines; (3) irregular spacing in between words; (4) retouched letters; (5) curves and angles in the arches of M, N, V, U; (6) junction points; (7) collisions and adhesions; (8) sudden strokes; (9) irregular dimensions; and (10) poor shapes. The score ranges from zero to 17 points; a score of eight and a half points ( $50 \%$ of the total) or higher is considered dysgraphia. As an additional element to be analyzed, the item (11) was included in this study: the number of lines used.

For SG1, the items (5) curves and angles in the arches of M, N, V, U; (6) junction points; and (8) sudden strokes were removed, as the type of letter they used does not allow for such analyses. Thus, for this group, those who scored the proportional values in the test (i.e., a score of 6 [ $50 \%$ of the total items considered for analysis] or higher) were considered children/adolescents with dysgraphia.

\section{Data analysis}

The data were submitted to descriptive and inferential analysis in the three groups. In the comparative analysis between the three groups, the Kruskal-Wallis statistical test was used. To compare SG1 with SG2, and SG1 with SG3, the Mann-Whitney statistical test was used, considering only the following items in the Dysgraphia Scale: (1) fluctuating lines; (2) descending and/or ascending lines; (3) irregular spacing in between words; (4) retouched letters; (7) collisions and adhesions; (9) irregular dimensions; and (10) poor shapes. To compare SG2 with SG3, the Mann-Whitney statistical test was used, comparing all the 10 items in the Dysgraphia Scale. To compare the schooling level between the groups, Fisher's test was used, and to compare their age, the Kruskal-Wallis test was used. The significance level was set at $p \leq 0.05$.

\section{RESULTS}

The sample characterization in the inferential statistics revealed that the mean age in SG1 was 10 years $(S D=1.77)$; in $S G 2,11.33$ years $(S D=1.77)$; and in SG3, 10.16 years $(S D=1.89)$. No significant differences were found in the comparison of age between the groups $\left(x^{2}=3.16, p=0.21\right)$. When the age was compared two groups at a time, no statistical difference was found between SG1 and SG2 $(U=$ 
29.00; $p=0.14)$; $S G 1$ and $S G 3(U=47.00 ; p=0.94)$; or SG2 and SG3 $(U=46.00 ; p=0.13)$.

Considering the schooling level of the participants of the study, the distribution of the groups' sample is observed in Table 1. No significant differences were found between the three groups ( $p=0.36$ ), between SG1 and SG2 ( $p=0.89)$, SG1 and SG3 $(p=0.29)$, or SG2 and SG3 $(p=0.19)$.

Comparing the score of the analysis items in the Scale between the three groups, a difference was verified in items (3) irregular spacing in between words, and (7) collisions and adhesions, as well as in the total score (Table 2). As for the comparison of the score of the items between SG1 and SG2, there was a statistically significant difference in item (7) collisions and adhesions, and in the total score (Table 3). There was a statistically significant difference between SG1 and SG3 only in the total score (Table 4). And between SG2 and SG3, there was a statistically significant difference only in item (3) irregular spacing in between words (Table 5).

Table 1. Distribution of the frequency of participants regarding schooling level

\begin{tabular}{cccccccc}
\hline \multirow{2}{*}{ School grade/SG } & \multicolumn{2}{c}{ SG1 } & $\mathbf{n}$ & \multicolumn{3}{c}{ SG2 } & \multicolumn{3}{c}{ SG3 } \\
\cline { 2 - 7 } & 1 & $\%$ & $\mathbf{n}$ & $\%$ & $\mathbf{n}$ & $\%$ \\
\hline $1^{\text {st }}$ & - & 12.5 & - & - & - & - \\
$2^{\text {nd }}$ & - & - & - & - & 1 & 16.7 \\
$3^{\text {rd }}$ & 2 & 25.0 & 3 & 25.0 & 6 & 8.3 \\
$4^{\text {th }}$ & 3 & 37.5 & 3 & 25.0 & 1 & 80.0 \\
$5^{\text {th }}$ & 1 & 12.5 & 2 & 16.7 & 2 & 16.7 \\
$6^{\text {th }}$ & 1 & 12.5 & 3 & 25.0 & - & - \\
$7^{\text {th }}$ & - & - & 1 & 8.3 & - & - \\
$8^{\text {th }}$ & 8 & 100 & 12 & 100 & 12 & 100 \\
\hline Total & & & & & & & \\
\hline
\end{tabular}

Caption: SG: Study Group

Table 2. Comparison of the means of the items in the Dysgraphia Scale between the groups

\begin{tabular}{ccccc} 
& \multicolumn{1}{c}{ SG1 } & SG2 & SG3 & \multirow{2}{*}{ p-value } \\
\cline { 2 - 4 } (1) FL & M (SD) & M (SD) & M (SD) & 0.72 \\
(2) DAL & $0.75(1.03)$ & $1.08(0.90)$ & $0.92(1.00)$ & 0.78 \\
(3) ISW & $0.44(0.18)$ & $0.42(0.42)$ & $0.50(0.30)$ & $0.04^{*}$ \\
(4) RL & $0.69(0.46)$ & $0.29(0.45)$ & $0.75(0.40)$ & 0.67 \\
(5) CAA & $1.62(0.52)$ & $1.67(0.65)$ & $1.42(0.79)$ & 0.21 \\
(6) JP & --- & $0.46(0.45)$ & $1.00(1.35)$ & 0.58 \\
(7) CA & --- & $1.58(0.67)$ & $1.75(0.45)$ & $0.03^{*}$ \\
(8) SS & $0.56(1.12)$ & $2.12(1.35)$ & $1.50(1.11)$ & 0.09 \\
(9) ID & --- & $0.92(0.90)$ & $1.50(0.52)$ & 0.24 \\
(10) PS & $0.87(0.99)$ & $0.75(0.96)$ & $1.33(0.65)$ & 0.45 \\
(11) TL & $1.00(0.00)$ & $0.87(0.31)$ & $0.96(0.14)$ & 0.14 \\
\hline TOTAL & $7.62(4.37)$ & $10.42(7.70)$ & $6.00(4.33)$ & $0.00^{*}$ \\
\hline
\end{tabular}

Captions: SG: Study Group; TL: total number of lines; FL: fluctuating lines; DAL: descending and ascending lines; ISW: irregular spacing in between words; RL: retouched letters; CAA: curves and angles in the arches of M, N, V, U; JP: junction points; CA: collisions and adhesions; SS: sudden strokes; ID; irregular dimensions; PS: poor shapes. M: mean; SD: standard deviation.

Statistical test: Kruskal-Wallis, p-value $\leq 0.05$. 
Table 3. Comparison of the means in the items of the Scale between the groups

\begin{tabular}{cccc}
\hline & SG1 & SG2 & p-value \\
\cline { 2 - 3 } & M (SD) & M (SD) & 0.42 \\
(1) FL & $0.75(1.03)$ & $1.08(0.90)$ & 0.76 \\
(2) DAL & $0.44(0.18)$ & $0.42(0.42)$ & 0.07 \\
(3) ISW & $0.69(0.46)$ & $0.29(0.45)$ & 0.66 \\
(4) RL & $1.62(0.52)$ & $1.67(0.65)$ & $0.01^{\star}$ \\
(7) CA & $0.56(1.12)$ & $2.12(1.35)$ & 0.76 \\
(9) ID & $0.87(0.99)$ & $0.75(0.96)$ & 0.23 \\
(10) PS & $1.00(0.00)$ & $0.87(0.31)$ & 0.50 \\
(11) TL & $7.62(4.37)$ & $10.42(7.70)$ & $0.00^{\star}$ \\
\hline TOTAL & $5.94(3.19)$ & $10.17(2.81)$ & 0 \\
\hline
\end{tabular}

Captions: SG: Study Group; TL: total number of lines; FL: fluctuating lines; DAL: descending and ascending lines; ISW: irregular spacing in between words; RL: retouched letters; CA: collisions and adhesions; ID; irregular dimensions; PS: poor shapes. M: mean; SD: standard deviation.

Statistical test: Mann-Whitney, p-value $\leq 0.05$

Table 4. Comparison of the means in the items of the Scale between the groups

\begin{tabular}{cccc} 
& SG1 & SG3 & p-value \\
\cline { 2 - 3 } (1) FL & M (SD) & M (SD) & 0.69 \\
(2) DAL & $0.75(1.03)$ & $0.92(1.00)$ & 0.61 \\
(3) ISW & $0.44(0.18)$ & $0.50(0.30)$ & 0.78 \\
(4) RL & $0.69(0.46)$ & $0.75(0.40)$ & 0.65 \\
(7) $\mathrm{CA}$ & $1.62(0.52)$ & $1.42(0.79)$ & 0.06 \\
(9) ID & $0.56(1.12)$ & $1.50(1.11)$ & 0.26 \\
(10) PS & $0.87(0.99)$ & $1.33(0.65)$ & 0.41 \\
(11) TL & $1.00(0.00)$ & $0.96(0.14)$ & 0.22 \\
\hline TOTAL & $7.62(4.37)$ & $6.0(4.33)$ & $0.00^{*}$ \\
\hline
\end{tabular}

Captions: SG: Study Group; TL: total number of lines; FL: fluctuating lines; DAL: descending and ascending lines; ISW: irregular spacing in between words; RL: retouched letters; CA: collisions and adhesions; ID; irregular dimensions; PS: poor shapes. M: mean; SD: standard deviation.

Statistical test: Mann-Whitney, p-value $\leq 0.05$.

Table 5. Comparison of the means in the items of the Scale between the groups

\begin{tabular}{cccc}
\hline & SG2 & SG3 & p-value \\
\cline { 2 - 3 } (1)FL & $\mathbf{M}(\mathbf{S D})$ & $\mathbf{M}(\mathbf{S D})$ & 0.66 \\
(2) DAL & $1.08(0.90)$ & $0.92(1.00)$ & 0.53 \\
(3) ISW & $0.42(0.42)$ & $0.50(0.30)$ & $0.01^{*}$ \\
(4) $\mathrm{RL}$ & $0.29(0.45)$ & $0.75(0.40)$ & 0.38 \\
(5) CAA & $1.67(0.65)$ & $1.42(0.79)$ & 0.21 \\
(6) JP & $0.46(0.45)$ & $1.00(1.35)$ & 0.58 \\
(7) CA & $1.58(0.67)$ & $1.75(0.45)$ & 0.16 \\
(8) SS & $2.12(1.35)$ & $1.50(1.11)$ & 0.09 \\
(9) ID & $0.92(0.90)$ & $1.50(0.52)$ & 0.10 \\
(10) PS & $0.75(0.96)$ & $1.33(0.65)$ & 0.51 \\
(11) TL & $0.87(0.31)$ & $0.96(0.14)$ & 0.06 \\
\hline TOTAL & $10.42(7.70)$ & $6.00(4.33)$ & 0.26 \\
\hline
\end{tabular}

Captions: SG: Study Group; TL: total number of lines; FL: fluctuating lines; DAL: descending and ascending lines; ISW: irregular spacing in between words; RL: retouched letters; CAA: curves and angles in the arches of M, N, V, U; JP: junction points; CA: collisions and adhesions; SS: sudden strokes; ID; irregular dimensions; PS: poor shapes. M: mean; SD: standard deviation.

Statistical test: Mann-Whitney, p-value $\leq 0.05$. 
As for the descriptive analysis of the presence of dysgraphia according to the Scale, there was an average of $50 \%$ to $100 \%$ of signs of dysgraphia in the groups of assessed children - four children $(50 \%)$ in SG1, 10 children (83.3\%) in SG2, and all the participants (100\%) in SG3 presented dysgraphia according to the analysis of the instrument. Hence, the group of children that used mixed letters (block and cursive) had the highest prevalence of dysgraphia, according to the criteria in Lorenzini's Scale (1993) ${ }^{18}$. In general, most of the children assessed for this study did not master their handwriting.

Concerning the total number of lines written in the composition, it was noted that SG1 produced a mean of 7 lines $(S D=4.37)$, SG2, a mean of 10 lines $(S D=7.70)$, and $S G 3$, a mean of 6 lines $(S D=4.32)$.

\section{DISCUSSION}

This study aimed to analyze the handwriting characterized by the type of letters used by children and adolescents with complaints of learning difficulties to verify signs suggestive of dysgraphia.

Considering the age group (mean age between 10 and 11 years) of the children included in the study, adequate and legible handwriting would be expected. It is at this age, or even earlier (at around eight to 10 years old) that the writing movements become stable and automatic ${ }^{19}$, and the child starts mastering and personalizing their handwriting, having an oriented control of this process ${ }^{2}$. It is also in this critical period, between the end of childhood and preadolescence, that persistent characteristics in the changes in handwriting can be perceived, revealing specific learning disorder conditions, such as dysgraphia ${ }^{20}$.

However, considering that all the children had some learning difficulty, there is a greater prevalence of changes in fine motor control than in the population without changes in their academic performance ${ }^{17,21-23}$. Considering the whole population, the prevalence of dysgraphia described in the international literature is estimated at $7 \%$ to $15 \%$ of the school-age children. In national studies, the percentages of dysgraphia were found to be $24 \%$ of the subjects with learning complaints ${ }^{5,24}$. Other studies reported even greater prevalence, reaching 70 and $95 \%$ of prevalence of signs of dysgraphia among children with a learning disorder or some difficulty at school ${ }^{17,21}$. Such a prevalence corresponds to the one in this research.

Based on what was previously exposed, this article, in consonance with the literature, approached the relationship between high comorbidity with learning disorders (such as dyslexia and learning difficulties) and changes in fine motor control and dysgraphia. A considerable number of schoolchildren with dyslexia may have changes in handwriting characteristics, such as fluctuating lines, ascending and/or descending lines, irregular spacing in between words, retouched words, curves and angles in the arches of $\mathrm{M}, \mathrm{N}, \mathrm{V}$, $U$, junction points, collisions and adhesions, sudden strokes, irregular dimensions, and poor shapes. Moreover, although dysgraphia can occur alone, there is frequently an association with other changes related to academic performance ${ }^{1,17,20,21}$.

Even though children with learning difficulties have adequate neuropsychomotor development when compared with children without this difficulty, there is a difference in their overall and fine motor performance. This indicates the need for and importance of psychomotor stimulation by professionals that deal with child development ${ }^{23}$.

On the other hand, there is also contrary evidence ${ }^{5}$ using Lorenzini's Scale $(1993)^{18}$, as this study did, with no relationship between academic performance and dysgraphia. Nevertheless, there were some limitations, as only 25 children were assessed, all of them studying in the same class of a public school and whose academic performance was below the expected.

Lastly, it should be considered that changes in handwriting impair the children's performance in the classroom, and the teachers must be prepared to help them every way they can, with strategies to compensate such difficulty ${ }^{25}$. To this end, it is necessary to invest in scientific production on the theme of dysgraphia and include it in teachers' training, as the literature makes evident the limited knowledge about the neuropsychomotor development and the perception of changes in fine motor control and, more specifically, in handwriting, which would be related to signs of dysgraphia ${ }^{16,17}$.

Among the limitations of this study, there is a need for assessing other aspects, such as motor skills related to the writing process.

\section{CONCLUSION}

It was verified in this study that the children with learning difficulties presented changes in their handwriting, regarding the irregular spacing in between words and the presence of collisions and adhesions.

It was also identified that, regardless of age, the children that used cursive and mixed letters had more signs of dysgraphia. Therefore, it is possible that the 
necessary linked movement, as it is tiresome, makes the writing process even harder for these children, also considering the educational context to which they belong. Thus, observing the type of handwriting the child uses is essential to future interventive strategies.

\section{REFERENCES}

1. Döhla D, Heim S. Developmental dyslexia and dysgraphia: what can we learn from the one about the other? Front Psychol. 2016;6(2045):1-12.

2. Palmis S, Danna J, Velay J, Longcamp M. Motor control of handwriting in the developing brain: $A$ review. Cogn Neuropsychol. 2017;34(3-4):187-204.

3. Planton S, Jucla M, Roux F, De'Monet J. The "handwriting brain": a meta-analysis of neuroimaging studies of motor versus orthographic processes. Cortex. 2013;49(10):2772-87.

4. Feder KP, Majnemer A. Handwriting development, competency, and intervention. Dev Med Child Neurol. 2007;49(4):312-7.

5. Rodrigues SD, Castro MJMG, Ciasca SM. Relação entre indícios de disgrafia funcional e desempenho acadêmico. Rev. CEFAC. 2009;11(2):221-7.

6. Tôrres VC, Silva AP, Gouveia AA, Lemes JAC. Aquisição da escrita - o desenvolvimento da escrita infantil. In: Donadon-Leal JB (org). Reflexões - a lingüística na sala de aula. Mariana: Aldrava Letras e Artes; 2007. p.72-8.

7. Brasil. Pacto nacional pela alfabetização na idade certa: a apropriação do sistema de escrita alfabética e a consolidação do processo de alfabetização. Ano 2: unidade 3. Ministério da Educação, Secretaria de Educação Básica, Diretoria de Apoio à Gestão Educacional- Brasília: MEC, SEB; 2012.

8. Chartrel E, Vinter A. The impact of spatio-temporal constraints on cursive letter handwriting in children. Learn Instr. 2008;18(6):537-47.

9. Rodrigues SD, Ciasca SM. Disgrafia na infância: aspectos psicomotores. In: Capovilla FC (org). Transtornos de aprendizagem: processos em avaliação e intervenção preventiva e remediativa. 2a Ed. São Paulo: Memnon, 2011. p. 224-30.

10. Prunty M, Barnett AL. Accuracy and consistency of letter formation in children with developmental coordination disorder. J Learn Disabil. 2020;53(2):120-30.

11. Havaei N, Rezaei M, Rostamil HR. Dexterity and two-point discrimination of the hand in school-aged children with dysgraphia. Med J Islam Repub Iran. 2016;30(434):1-7.
12. McCloskey M, Rapp B. Developmental dysgraphia: An overview and framework for research. Cogn Neuropsychol. 2017;34(3-4):65-82.

13. Rosenblum S, Dror G. Identifying developmental dysgraphia characteristics utilizing Handwriting Classification Methods. IEEE Trans Hum Mach Syst. 2016;47(2):293-8.

14. APA. Associação americana de psiquiatria. DSM-5. Manual de Diagnóstico e Estatística dos Transtornos Mentais - Quinta Edição (DSM-5). Tradução Maria Inês Corrêa Nascimento et al. Porto Alegre: ARTMED, 2014.

15. Cardoso MH, Capellini SA. Identification and characterization of dysgraphia in students with learning difficulties and learning disorders. Disturb. Comum. 2016;28(1):27-37.

16. Duzzi MHB, Rodrigues SD, Ciasca SM. Percepção de professores sobre a relação entre desenvolvimento das habilidades psicomotoras e aquisição da escrita. Rev Psicopedagia. 2013;30(92):121-8.

17. Germano GD, Giaconi C, Capellini SA. Characterization of Brazilians students with dyslexia in handwriting proficiency screening questionnaire and handwriting scale. Psychol Res. 2016;6(10):590-7.

18. Lorezini MV. Uma escala para determinar a disgrafia baseada na escala de Ajuriaguerra [Dissertação]. São Carlos (SP): Universidade Federal de São Carlos; 1993.

19. Kandel S, Perret C. How does the interaction between spelling and motor processes build up during writing acquisition? Cognition. 2015;136:325-36.

20. Berninger VW, Richards T, Abbott RD. Differential diagnosis of dysgraphia, dyslexia, and OWL LD: behavioral and neuroimaging evidence. Read Writ. 2015;28(8):1119-53.

21. Capellini AS, Coppede AC, Valle TR. Função motora fina de escolares com dislexia, distúrbio e dificuldades de aprendizagem. Pro Fono R. Atual. Cientif. 2010;22(3):201-8.

22. Fusco N, Germano GD, Capellini AS. Efficacy of a perceptual and visual-motor skill intervention program for students with dyslexia. CoDAS. 2015;27(2):128-34.

23. Okuda PMM, Pinheiro FH. Motor performance of students with learning difficulties. Procedia Soc Behav Sci. 2015;174:1330-8. 
24. Oliveira RMSG. Aplicação da escala de disgrafia em crianças com e sem dificuldade na escrita [dissertação]. Marília (SP): Universidade de Marília; 2000.

25. Prunty M, Barnett AL. Understanding handwriting difficulties: A comparison of children with and without motor impairment. Cogn Neuropsychol. 2017;34(3-4):205-18. 